\title{
Sorption of lead and methylene blue onto hickory biochars from different pyrolysis temperatures: Importance of physicochemical properties
}

\author{
Zhuhong Ding ${ }^{\mathrm{a}, \mathrm{b}}$, Yongshang $\mathrm{Wan}^{\mathrm{c}}$, Xin $\mathrm{Hu}^{\mathrm{d}}{ }^{\mathrm{b}}$, Shengsen Wang ${ }^{\mathrm{b}}$, Andrew R. Zimmerman ${ }^{\mathrm{e}}$, Bin \\ $\mathrm{Gao}^{\mathrm{b}} *$ \\ ${ }^{a}$ School of Environment, Nanjing University of Technology, 30 Puzhu Southern Road, Nanjing \\ 211816, P.R. China \\ ${ }^{b}$ Department of Agricultural and Biological Engineering, University of Florida, Gainesville, $F L$ \\ 32611, United States \\ ${ }^{c}$ South Florida Water Management District, West Palm Beach, FL 33406, United States \\ ${ }^{d}$ State Key Laboratory of Analytical Chemistry for Life Science, School of Chemistry and \\ Chemical Engineering and Center of Material Analysis, 20 Hankou Road, Nanjing University, \\ Nanjing 210093, P.R. China \\ ${ }^{e}$ Department of Geological Sciences, University of Florida, Gainesville, FL 32611
}

\footnotetext{
* Corresponding author. Tel.: (352) 392-1864x285; fax: (352) 392-4092. Email address: bg55@ufl.edu (B. Gao). 
Keywords: Biochar; heavy metal; organic contaminant; dye; sorption 


\section{Introduction}

Biochar, a product of incomplete biomass combustion in an oxygen-limited environment, has received increasing attention in the scientific community for its many potential applications and environmental benefits such as carbon sequestration, soil fertility improvement, remediation of contaminated soils, and treatment of drinking water and industrial wastewater [1-4]. Understanding of the chemical and physical characteristics of biochar and how they are related to biochar production conditions is crucial to the design of biochar production technologies, which can be employed to optimize the needed biochar characterization for target uses. For example, using biochars for carbon sequestration comes mainly with the realization of the similarity between the relatively enriched carbon $(\mathrm{C})$ in biochar and organic $\mathrm{C}$ in soils and sediments while potential environmental applications of biochar as a sorbent for water and wastewater treatment is based on an understanding of the surface property of biochars and their strong sorptive affinity to both organic and inorganic contaminants [4-8]. Biochars have been suggested as low-cost adsorbents for the removal of aqueous metal ions (e.g. $\mathrm{Pb}^{2+}, \mathrm{Cd}^{2+}, \mathrm{Cu}^{2+}$, and $\mathrm{As}^{2+}$ ), dyes, phenolics, pesticides, and polynucelar aromatics from contaminated soils and waters $[2,3,5]$.

There are a great number of studies in the literature, focusing on biochar characterization using various analytical techniques and sorptive properties with respect to different types of biochar. Previously published data indicate that the adsorption capacity of biochars ranges from a few grams to hundreds of grams per kilogram of biochars, depending on the types of feedstock such as wood materials, crop residues (straw, corn stover, nutshells, coconut shells, and rice husks), bagasse from sugar cane, dairy manure, and sewage sludge [2, 3, 6, 7]. A number of recent studies, have examined the adsorption isotherms, adsorption kinetics and adsorption thermodynamics of pollutants onto biochars $[2,3,6-8]$, and revealed that the sorption 
mechanisms, can be both physisorption and chemisorption. Biochar characterization with some of the fundamental physicochemical properties such as surface elemental composition and species, surface functional groups, specific surface area (SE) and cation-exchange capacity (CEC) has greatly improved our understanding the nature and behavior biochar, especially with respect to its sorptive affinity to organic and inorganic contaminants [2, 3]. It is generally concluded that surface properties of biochar are important for the understanding of chemical adsorption and ion exchange adsorption of pollutants $[2,3]$.

The technological factors such as pyrolysis temperature can be controlled to achieve the desired sorption capacities in preparation of biochars $[9,10]$. Since biochars are obtained through pyrolysis of feedstocks at a wide range of temperatures [11], the peak pyrolysis temperature is a key factor determining the physicochemical properties of biochars [2, 3]. For example, Kloss et al. indicate that pyrolysis temperatures of 400,460 , and $525^{\circ} \mathrm{C}$ resulted in the different physicochemical properties of biochar derived from wheat straw, poplar wood, and spruce wood [12]. Wang et al. concluded that increasing pyrolysis temperature from 500 to $700{ }^{\circ} \mathrm{C}$ resulted in decrease in biochar yield, total acidic functional groups, cation exchange capacity, and $\mathrm{N}$ content and increase in BET surface area, ash content, $\mathrm{pH}$, and total $\mathrm{Ca}$ and $\mathrm{P}$ contents [10].

Although several studies have examined the effects of temperature on the physicochemical properties of biochars derived from agricultural and forestry residuals [12-14]; there are still needs of compressive investigations that examine both physical and chemical properties of biochars in details and then link them with their sorption ability to contaminants in aqueous solution. Furthermore, most of the previous studies on the effects of biochar surface properties on their sorption performance are mainly focused on inorganic contaminants, such as heavy metals [15-17], it is thus very important to determine the relationships between biochars' 
physicochemical properties and their sorptive performance for both inorganic and organic contaminants. To satisfice these needs, a range of physical and chemical properties of biochars derived from hickory at different pyrolysis temperature were investigated in details in this work. The sorption of organic (methylene blue) and inorganic (lead) contaminants on the biochars were examined in details to expand on previous research on the relationship between physicochemical properties and sorption ability. Hickory is a type of deciduous tree distributed throughout the world. Hickory wood chips are used for charcoal grill and gas grill, as well as for smoking meats, poultry, vegetables, and fish. In this work, biochar was produced from hickory chips at a range of peak pyrolysis temperatures $\left(350^{\circ} \mathrm{C}, 450^{\circ} \mathrm{C}\right.$ and $\left.600^{\circ} \mathrm{C}\right)$. We employed a number of analytical techniques include scanning electron microscope (SEM), thermal analysis, Fourier-transform infrared spectroscopy (FT-IR), X-ray diffraction (XRD), X-ray photoelectron spectroscope (XPS), zeta potential analyzer, Boehm titration, and batch sorption experiments to characterizing surface properties of the obtained biochars and their sorption of $\mathrm{Pb}(\mathrm{II})$ and methylene blue. The objectives of this study were (1) to reveal the effects of the peak pyrolysis temperature on the physicochemical properties of biochar, and (2) to elucidate the linkage between the physicochemical properties of biochars and their sorption abilities.

\section{Experimental}

\subsection{Chemical reagents}

Chemical reagents of analytic grade including methylene blue (MB), $\mathrm{NaOH}, \mathrm{HNO}_{3}$ and $\mathrm{Pb}\left(\mathrm{NO}_{3}\right)_{2}$ were purchased from Fisher Scientific. All solutions were prepared using deionized (DI) water $(18 \mathrm{M} \Omega * \mathrm{~cm})$. 


\subsection{Preparation of biochars}

Dried commercial hickory wood chips were ground in a knife mill (Model No. 4, Arthur H. Thomas Company, Philadelphia, PA) to achieve $0.5-1 \mathrm{~mm}$ hickory powders. The hickory powders were placed inside tubular quartz reactors $(50 \mathrm{~g}$ in $6 \mathrm{~cm}$ diameter $\times 28 \mathrm{~cm}$ length cylinders) and then inserted into a bench-top furnace (Barnstead $1500 \mathrm{M}$ ) purged with $\mathrm{N}_{2}$ gas (10 psi). The pyrolysis furnace temperature was increased at a rate of $20^{\circ} \mathrm{C} / \mathrm{min}$ and then held at $350^{\circ} \mathrm{C}, 450^{\circ} \mathrm{C}$, and $600^{\circ} \mathrm{C}$ for $5 \mathrm{~h}, 3 \mathrm{~h}$ and $2 \mathrm{~h}$, respectively, with flowing $\mathrm{N}_{2}$ gas. The biochar samples produced were rinsed with tap water and DI water, and then oven dried at $80^{\circ} \mathrm{C}$. The obtained biochars were placed in sealed containers and notated as B350, B450 and B600, respectively.

\subsection{Characterization of biochars}

Contents of $\mathrm{C}, \mathrm{H}$ and $\mathrm{N}$ in the biochars were determined using a CHN Elemental Analyzer (Carlo-Erba NA-1500) via high-temperature catalyzed combustion of $50 \mathrm{mg}$ samples followed by thermal conductivity detection of the resulting gases. Ashing of $0.2 \mathrm{~g}$ samples were carried out at $550^{\circ} \mathrm{C}$ and then the residue was dissolved by using $5 \% \mathrm{HNO}_{3}$. Major mineral elements in the resulting digestion solution were determined using inductively coupled plasma optical emission spectroscopy (ICP-OES, Perkin Elmer Optima 2100 DV, USA). Specific surface areas were measured on a Quantachrome Autosorb-1 surface area analyzer using $\mathrm{N}_{2}$ sorption and calculated according to the BET theory. Zeta potential was analyzed following Mukherjee et al. [8] on a Zeta Plus Zeta Potential Analyzer (Brookhaven Instruments Corporation). Cation exchange capacity (CEC) was analyzed using US EPA SW-846 method 9081. Acidic functional group distributions on biochars were determined using a modified Boehm titration method 
[18-20]. Thermogravimetric TG and derivative (DTG) curves were obtained using a Mettler TGA/DSC thermogravimetric analyzer (TGA/DSC 1, STARe System, METTLER TOLEDO, USA) at a heating rate of $10^{\circ} \mathrm{C} / \mathrm{min}$ from $50^{\circ} \mathrm{C}$ to $900^{\circ} \mathrm{C}$ under a controlled atmosphere of $\mathrm{N}_{2}(50$ $\mathrm{ml} \mathrm{min}{ }^{-1}$ ) with initial mass of $30 \mathrm{mg}$. The samples were treated by fixation and spray-gold and then a JEOL JSM-6330F field-emission scanning electron microscope (SEM) equipped with energy dispersive spectrometer (EDS) was used to examine and compare surface morphology and elemental composition of the biochars.

Biochar samples were grinded into fine powder as far as possible for the next instrumental characterization. Surface chemistry of biochars was studied by constructing FT-IR spectra recorded in the range $400-4000 \mathrm{~cm}^{-1}$ with $2 \mathrm{~cm}^{-1}$ resolution using a Nicolet 6700 FT-IR (Thermo Scientific) after samples were milled with potassium bromide (KBr) (the mass ratio of the sample to $\mathrm{KBr}$ was about 0.01 ) to form a very fine powder and then compressed into a thin pellet. Crystalline minerals in biochars were detected using XRD (Philips Electronic Instruments) after pressing the fine biochar powders into disks directly. Surface elemental composition and speciation of the fine biochar powder was studied using XPS with a PHI 5100 series ESCA spectrometer (Perkin Elmer).

\subsection{Batch sorption experiments}

Batch isotherm sorption experiments were carried out at a room temperature $\left(22 \pm 2{ }^{\circ} \mathrm{C}\right)$ following Ding et al. [2014]. Briefly, $0.1 \mathrm{~g}$ biochars was added to $50 \mathrm{~mL} \mathrm{~Pb}(\mathrm{II})$ or MB solutions of different initial concentrations ranging from 1 to $250 \mathrm{mg} \mathrm{L}^{-1}$ in $100 \mathrm{~mL}$ polyethylene centrifuge tubes. $\mathrm{Pb}(\mathrm{II})$ and $\mathrm{MB}$ were selected in this study for representation of inorganic (heavy metal) and organic (dye) in wastewater. The initial concentrations of $\mathrm{Pb}(\mathrm{II})$ and $\mathrm{MB}$ were set as 2, 
10, 25, 50, 100, and $250 \mathrm{mg} \mathrm{L}^{-1}$ and 5, 10, 25, 50, 100, and $250 \mathrm{mg} \mathrm{L}^{-1}$, respectively. The initial solution $\mathrm{pH}$ was set as $5.0 \pm 0.1$ for $\mathrm{Pb}$ (II) and $6.5 \pm 0.1$ for $\mathrm{MB}$, adjusted using $0.01 \mathrm{M} \mathrm{NaOH}$ or $\mathrm{HNO}_{3}$. The tubes were shaken in a mechanical shaker for $24 \mathrm{~h}$ at the room temperature to reach a dynamic equilibrium. The mixture was then centrifuged at $4000 \mathrm{rpm}$ for $10 \mathrm{~min} . \mathrm{Pb}$ (II) in the supernatant was determined using ICP-OES (Optima 2300, Perkin-Elmer SCIEX, USA) and MB was analyzed using a UV-Vis spectrophotometer Evolution-60 (Thermo Fisher Scientific, USA) at $664 \mathrm{~nm}$. The amount of adsorbed $\mathrm{Pb}(\mathrm{II})$ or $\mathrm{MB}$ at adsorption equilibrium $\left(q_{e}\right)$ per unit biochar mass were calculated using $q_{e}=\left[\left(C_{0}-C_{\mathrm{e}}\right) V\right] / m$, where $C_{0}$ and $C_{e}$ are the initial and equilibrium concentrations of $\mathrm{Pb}(\mathrm{II})$ or $\mathrm{MB}\left(\mathrm{mg} \mathrm{L}^{-1}\right)$, respectively; $V$ is the volume of the solution (L); and $m$ is the mass of biochar sample (g).

\section{Results and discussion}

\subsection{Elemental composition of bulk biochar samples}

Pyrolysis of hickory wood at temperature of 350,450 and $600{ }^{\circ} \mathrm{C}$ yielded about $35 \%, 33 \%$ and $21 \%$ biochars, consistent with previous reports about decreasing yield with increasing pyrolysis temperature [11]. The raw hickory feedstock contained about $48.2 \% \mathrm{C}, 5.88 \% \mathrm{H}$, $0.22 \% \mathrm{~N}, 45.5 \% \mathrm{O}$, and less than $0.1 \%$ other main mineral elements (Ca, $\mathrm{K}, \mathrm{Mg}, \mathrm{Al}$ and $\mathrm{Fe}$ ). In contrast, the elemental composition of biochars showed relative decrease in $\mathrm{O}$ and $\mathrm{H}$ and increase in $\mathrm{C}$ and mineral elements ( $\mathrm{N}, \mathrm{Ca}, \mathrm{K}, \mathrm{Mg}, \mathrm{Al}$ and $\mathrm{Fe}$ ) (Table 1). The relative loss of $\mathrm{O}$ and $\mathrm{H}$ and gain of $\mathrm{C}$ and minerals increased with increasing pyrolysis temperature. For example, B600 was the most carbonized biochar with the $\mathrm{C}$ mass percentage of $84.7 \%$. Atomic ratios of $\mathrm{H} / \mathrm{C}(0.650 \rightarrow 0.259), \mathrm{O} / \mathrm{C}(0.243 \rightarrow 0.100)$, and $(\mathrm{O}+\mathrm{N}) / \mathrm{C}(0.246 \rightarrow 0.103)$ also decreased with increasing pyrolysis temperature, consistent with Keiluweit et al. who noted that when the peak 
pyrolysis temperature increased from $100^{\circ} \mathrm{C}$ to $700^{\circ} \mathrm{C}$, atomic ratios of $\mathrm{H} / \mathrm{C}$ and $\mathrm{O} / \mathrm{C}$ decreased from 1.59 to 0.21 and 0.63 to 0.05 for biochar derived from Ponderosa pine shavings and from 1.81 to 0.2 and 0.69 to 0.03 for biochar derived from tall fescue straw, respectively [21]. The lower $\mathrm{O} / \mathrm{C}$ ratio (0.100) in $\mathrm{B} 600$ indicated that the biochar surface at high pyrolysis temperature was less hydrophilic [22]. The decreased polarity index $[(\mathrm{O}+\mathrm{N}) / \mathrm{C}](0.246 \rightarrow 0.103)$ reflected a decreased polar-group content with increasing pyrolysis temperature [22].

Table 1 Elemental composition (weight $\%$ ), specific surface areas $\left(\mathrm{SA}, \mathrm{m}^{2} / \mathrm{g}\right)$ and cation-exchange capacity $(\mathrm{cmol} / \mathrm{kg})$ of the pristine biochars.

\begin{tabular}{lllllllllllll}
\hline & $\mathrm{Fe}$ & $\mathrm{Ca}$ & $\mathrm{Mg}$ & $\mathrm{Al}$ & $\mathrm{K}$ & $\mathrm{Mn}$ & $\mathrm{C}$ & $\mathrm{N}$ & $\mathrm{H}$ & $\mathrm{O}$ & $\mathrm{SA}$ & $\mathrm{CEC}$ \\
\hline B350 & 0.01 & 0.63 & 0.17 & 0.02 & 0.23 & 0.03 & 71.6 & 0.25 & 3.88 & 23.2 & $<0.5$ & 42.7 \\
$\mathrm{~B} 450$ & 0.02 & 0.77 & 0.22 & 0.03 & 0.27 & 0.03 & 77.6 & 0.27 & 3.52 & 17.3 & 1.60 & 41.9 \\
$\mathrm{~B} 600$ & 0.03 & 1.17 & 0.29 & 0.04 & 0.28 & 0.05 & 84.7 & 0.30 & 1.83 & 11.3 & 256 & 45.7 \\
\hline
\end{tabular}

Contents of $\mathrm{O}$ were obtain by subtraction method

\subsection{Morphology, phase and thermal stability of bulk biochar samples}

The morphology of the obtained biochars was observed using SEM under 1000 times magnifications. The results did not show clear regularity or amorphous characteristics (Fig. 1). The different size and shape of biochar particles may be influenced by the sample preparation such as grinding and washing activities. The XRD pattern, however, indicated that carbon in the studied biochars existed mainly in the amorphous form. Compared to B350, quartz and calcite existed in B600 (Fig. 2), which may result from the higher hydrolysis temperature. 


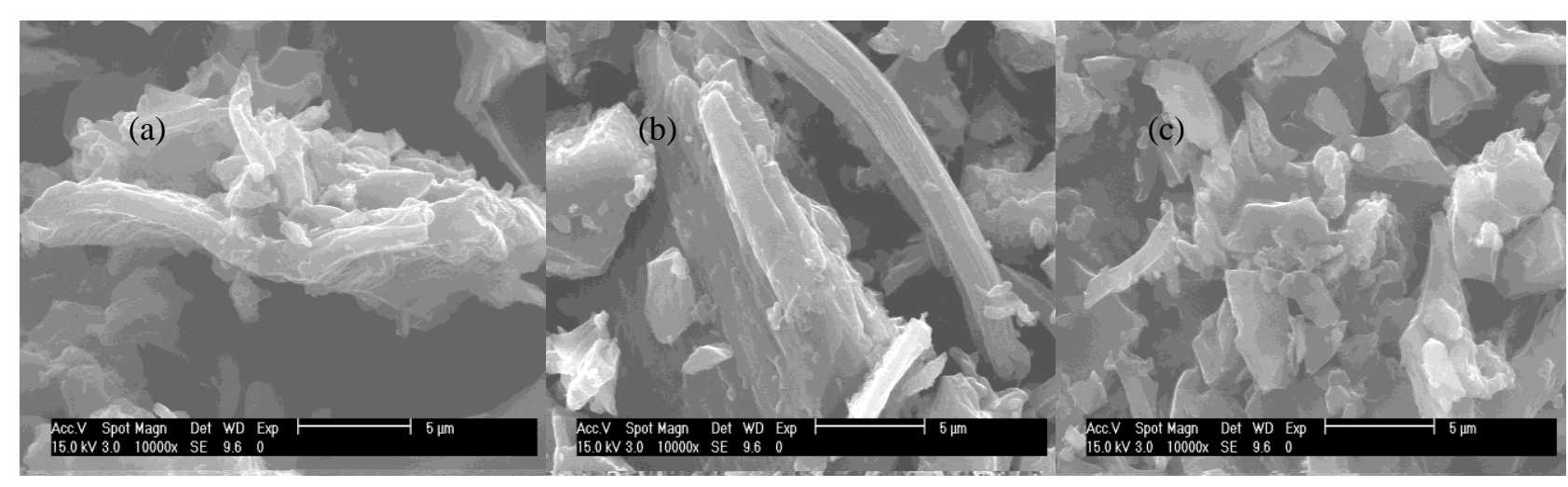

Fig. 1 - SEM images of (a) B350, (b) B450 and (c) B600.

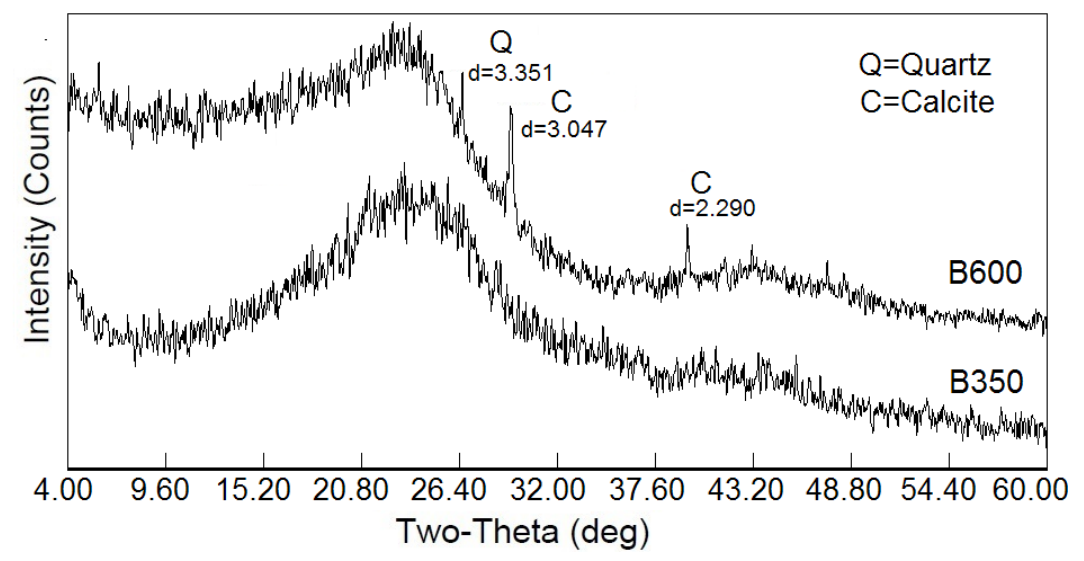

Fig. 2 - XRD patterns of biochar B350 and B600.

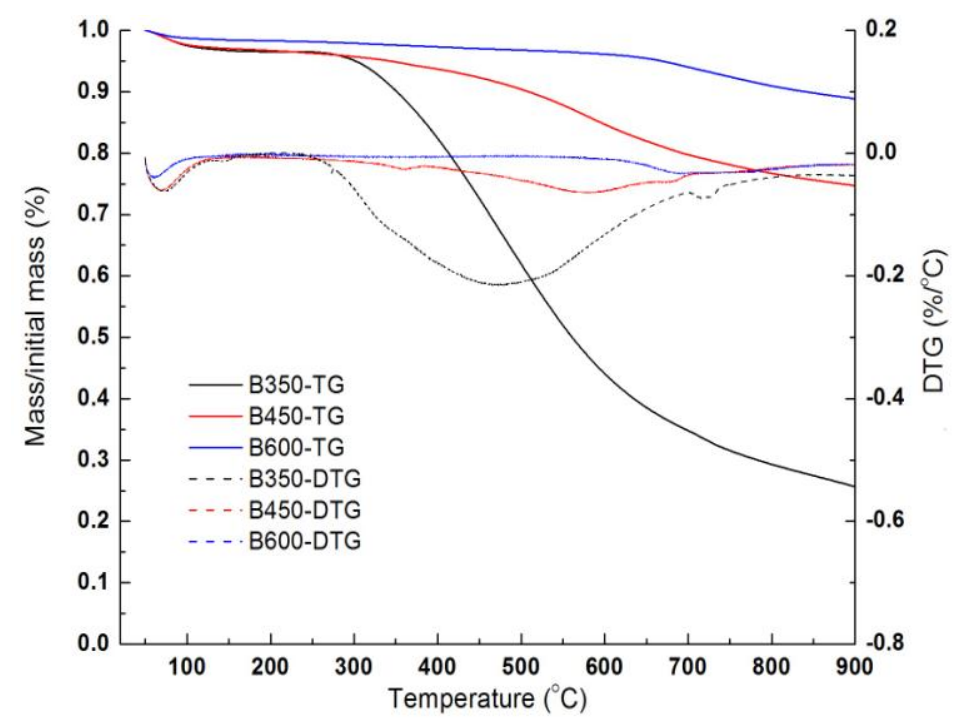


Fig. 3 - TG/DTG curves of the pristine biochar samples

The TG/DTG curves exhibited obvious differences in thermal stability among biochar samples, varying with pyrolysis temperature (Fig. 3). As expected, B350, B450, and B600 showed strong weight loss above $350^{\circ} \mathrm{C}, 450^{\circ} \mathrm{C}$, and $600^{\circ} \mathrm{C}$, respectively, with weight loss following the order of $\mathrm{B} 350>\mathrm{B} 450>\mathrm{B} 600$. The percentage of the final mass at $900^{\circ} \mathrm{C}$ to the initial mass was $25.7 \%$ for B350, 74.7\% for B450, 88.9\% for B600. Biochar mass loss at varying temperature may be associated with thermal destruction of different functional groups [23]. It was reported that the thermal decomposition of surface functional groups of activated carbon was generally $150-300^{\circ} \mathrm{C}$ for carboxylic groups, $300-500^{\circ} \mathrm{C}$ for acid anhydride and lactone and $500-800^{\circ} \mathrm{C}$ for phenolic hydroxyl and carbonyl groups and ethers [24]. While all biochars samples displayed an initial mass loss up to about $100^{\circ} \mathrm{C}$, attributable to water loss. For B350, B400, and B600, it can be well assumed that some functional groups were destroyed during pyrolysis with major thermochemical decompositions taking place at temperature $>350^{\circ} \mathrm{C}$, or specifically between 350 to $700{ }^{\circ} \mathrm{C}$ (the main peak in DTG curve, Fig. 3).

\subsection{Surface properties of biochars influenced by pyrolysis temperature}

The surface properties of biochar include the specific surface area, surface charges, surface elemental composition and functional groups. Specific surface areas of biochars increased from $<0.5 \mathrm{~m}^{2} / \mathrm{g}$ for B350 to $256 \mathrm{~m}^{2} / \mathrm{g}$ for B600 (Table 1). In a literature review, Ahmad et al. reported that specific surface area of 101 biochars under peak pyrolysis temperature from $100{ }^{\circ} \mathrm{C}$ to 900 ${ }^{\circ} \mathrm{C}$ ranged from 0 to $490.8 \mathrm{~m}^{2} / \mathrm{g}$ with a median value of $15 \mathrm{~m}^{2} / \mathrm{g}$ [2]. They further concluded that an increase of the pyrolysis temperature resulted in a considerable increase of the surface area of 
the biochars [2]. Our results were consistent with those reports.

Surface charges of biochar were characterized by using zeta potential and cation exchange capacity. Zeta potential values of the colloidal biochar samples at near neutral $\mathrm{pH}$ were $-27.5 \pm 2.0$ $\mathrm{mV}$ for $\mathrm{B} 350,-28.8 \pm 4.8 \mathrm{mV}$ for $\mathrm{B} 450$, and $-32.4 \pm 1.9 \mathrm{mV}$ for $\mathrm{B} 600$, respectively. It seems that zeta potential values decreased with the increasing pyrolysis temperature from $350^{\circ} \mathrm{C}$ to $600^{\circ} \mathrm{C}$. The zeta potential of oak-biochar for a given $\mathrm{pH}$ was significantly more electronegative with the increasing temperature from $250^{\circ} \mathrm{C}$ to $600^{\circ} \mathrm{C}$ [8], and this is consistent with our results. The CEC values of biochars in our study varied little with increasing peak pyrolysis temperature from $350^{\circ} \mathrm{C}$ to $600^{\circ} \mathrm{C}$ (Table 1), supporting the Lehmann's results [25], but contrary to the reports of Gaskin et al. [26] and Singh et al. [6]. The CEC of oak-, pine- and grass-biochar at the pyrolysis temperature of 250,400 and $650^{\circ} \mathrm{C}$, determined using $\mathrm{K}^{+}$exchange, ranged between 10.2 and $69.2 \mathrm{cmol} \mathrm{kg}^{-1}$ at near neutral $\mathrm{pH}$ [8]. The CEC of the straw-, spruce- and poplar- derived biochars ranged from 5.22 to $14.4 \mathrm{cmol} \mathrm{kg}^{-1}$ and decreased with increasing pyrolysis temperature from $400^{\circ} \mathrm{C}$ to $525^{\circ} \mathrm{C}$; but their $\mathrm{CEC}$ was calculated as the sum of the $\mathrm{Na}, \mathrm{K}, \mathrm{Mg}, \mathrm{Ca}$, $\mathrm{Al}, \mathrm{Fe}$, and $\mathrm{Mn}$ after a sequential water- $\mathrm{BaCl}_{2}$ extraction method [12]. Zeta potential and CEC confirmed the surface negative charges of biochars and the electronegative surface will facilitate the adsorption of cations.

Acidic functional groups (carboxyl, lactone and phenol) on biochars were determined by the Boehm titration method with different alkali solutions $\left(\mathrm{NaOH}, \mathrm{Na}_{2} \mathrm{CO}_{3}\right.$, and $\left.\mathrm{NaHCO}_{3}\right)$. Carboxylic groups were the dominant acidic groups for the studied biochars (Table 2). Carboxyl groups and total acidic groups of these biochars became lower as temperature increased [27], confirming the TG/DTG curves. The slight decrease of carboxylic groups as temperature increase suggests carboxylic groups may still remain at temperature of $600{ }^{\circ} \mathrm{C}$, as opposed to the 
report of Jaramillo et al [24] about destruction of carboxylic groups below temperature of $350^{\circ} \mathrm{C}$.

Table 2 Acidic functional groups determined by Boehm titration $\left(\mathrm{mmol} \mathrm{g}^{-1}\right)$ reported as the mean \pm standard deviation.

\begin{tabular}{lllll}
\hline & Carboxyl & Lactone & Phenol & Total acidic groups \\
\hline B350 & $0.738 \pm 0.038$ & $0.113 \pm 0.058$ & $0.069 \pm 0.038$ & $0.921 \pm 0.014$ \\
B450 & $0.721 \pm 0.023$ & $0.042 \pm 0.032$ & $0.029 \pm 0.022$ & $0.791 \pm 0.019$ \\
B600 & $0.620 \pm 0.015$ & $0.029 \pm 0.008$ & $0.046 \pm 0.013$ & $0.696 \pm 0.015$ \\
\hline
\end{tabular}

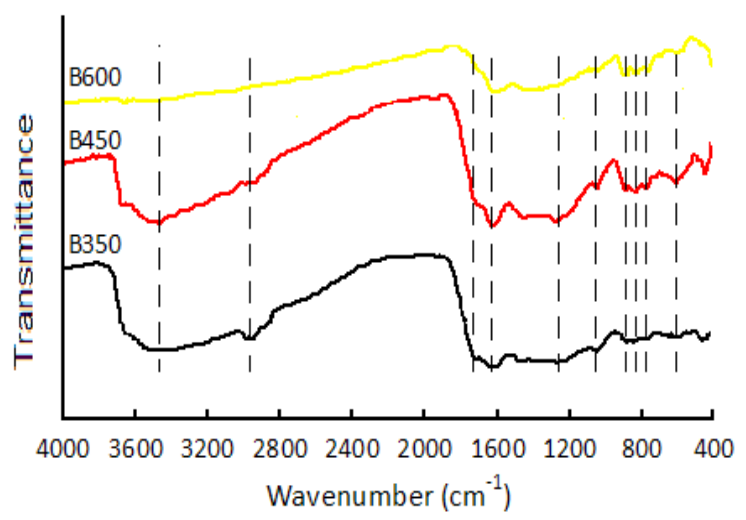

Fig. 4 - FT-IR spectra of the biochar samples

The changes of surface functional groups of the pristine biochar samples are verified by using FT-IR. B350 and B450 is rich in $\mathrm{H}$ and $\mathrm{O}$ contents (Table 1), which include $\mathrm{OH}$ groups (at $3000-3700 \mathrm{~cm}^{-1}$ ), $\mathrm{CH}_{2}$ groups (at $2800-3690 \mathrm{~cm}^{-1}$ ), $\mathrm{C}=\mathrm{O}$ for carboxyl groups (at $1700-1740$ $\mathrm{cm}^{-1}$ ), and phenolic $-\mathrm{OH}\left(\right.$ at $\left.1270 \mathrm{~cm}^{-1}\right)$. The band $\mathrm{C}-\mathrm{O}\left(1040\right.$ and $\left.1058 \mathrm{~cm}^{-1}\right)$ represents O-containing function groups (Fig. 4). Peaks at 890,820 , and $760 \mathrm{~cm}^{-1}$ are assigned to the aromatic C-H banding (Fig. 4). The nonexistence of such peaks in B600 reflects the decrease of surface functional groups with increasing pyrolysis temperature, consistent with the change of contents of $\mathrm{O}, \mathrm{H}$ and acidic functional groups in biochar samples (Fig. 4). 
Surface analysis using XPS indicated that biochars were mainly composed of $\mathrm{C}, \mathrm{O}$ and small amounts of inorganic matter (Fig. 5). The atomic percentage of surface $\mathrm{C}$ increased from $78.9 \%$ to $86.7 \%$ while surface $\mathrm{O}$ decreased from $20.5 \%$ to $12.0 \%$ with the increasing pyrolysis temperature from $350^{\circ} \mathrm{C}$ to $600^{\circ} \mathrm{C}$ (Fig. 5), consistent with the change of their total contents in Table 1. Surface $\mathrm{O} / \mathrm{C}$ ratio was 0.260 and 0.138 for $\mathrm{B} 350$ and $\mathrm{B} 600$, respectively, indicating that the high pyrolysis temperature decreased the surface oxygen-containing functional groups. Bulk $\mathrm{O} / \mathrm{C}$ ratios were 0.243 and 0.100 for $\mathrm{B} 350$ and $\mathrm{B} 600$, respectively. The fitting of high-resolution XPS spectra of $\mathrm{C}_{1 \mathrm{~s}}$ region shows two main peaks in the peak binding energy of $\sim 284.0 \mathrm{eV}$ (68.00-75.28\%) and $286.5 \mathrm{eV}$ (19.49-26.11\%) for B350 and B600 (Fig. 6a). According to the XPS database of Thermo Scientific and the NIST X-ray Photoelectron Spectroscopy Database, the binding energy of $\mathrm{C}_{1 \mathrm{~s}}$ at $\sim 284.8 \mathrm{eV}$ was assigned to $\mathrm{C}-\mathrm{C}$, at $\sim 286 \mathrm{eV}$ to organic $\mathrm{C}(\mathrm{C}-\mathrm{O}-\mathrm{C})$, and at $\sim 288.5 \mathrm{eV}$ to organic $\mathrm{C}(\mathrm{O}-\mathrm{C}=\mathrm{O})$. Therefore, the following species of surface $\mathrm{C}$ in biochars were identified as $\mathrm{C}-\mathrm{C}$ and/or graphite $\mathrm{C}$ at $284.75-284.81 \mathrm{eV}$ and $\mathrm{C}$ bound to $\mathrm{O}(\mathrm{C}-\mathrm{O})$ at $286.11-286.58 \mathrm{eV}$. The amorphous $\mathrm{C}$ and/or graphite $\mathrm{C}$ were the dominant species of $\mathrm{C}$ in the pristine biochars. The increasing pyrolysis temperature from $350{ }^{\circ} \mathrm{C}$ to $600{ }^{\circ} \mathrm{C}$ increased $\mathrm{C}$ and/or graphite $\mathrm{C}$ and decreased $\mathrm{C}-\mathrm{O}$ groups (Fig. 6a), consistent with the TG-DTG analyses and Boehm titration analyses. XPS spectra of $\mathrm{O}_{1 \mathrm{~s}}$ region show a peak in the peak binding energy of $\sim 533 \mathrm{eV}$ for B350 and B600 (Fig. 6b). According to the XPS database of Thermo Scientific, the binding energy of $\mathrm{O}_{1 \mathrm{~s}}$ at $\sim 533 \mathrm{eV}$ was assigned to organic $\mathrm{C}=\mathrm{O}$. Therefore, the binding energy peaks of $\mathrm{O}_{1 \mathrm{~s}}$ in $\mathrm{B} 350$ and $\mathrm{B} 600$ at $532.85-533.11 \mathrm{eV}$ were assigned to $\mathrm{C}=\mathrm{O}$ (Fig. $6 \mathrm{~b}$ ), suggesting that species of $\mathrm{O}$ were not influenced by the pyrolysis temperature. Therefore, the increasing pyrolysis temperature changes the surface contents of $\mathrm{C}$ and $\mathrm{O}$, but not their surface species. 


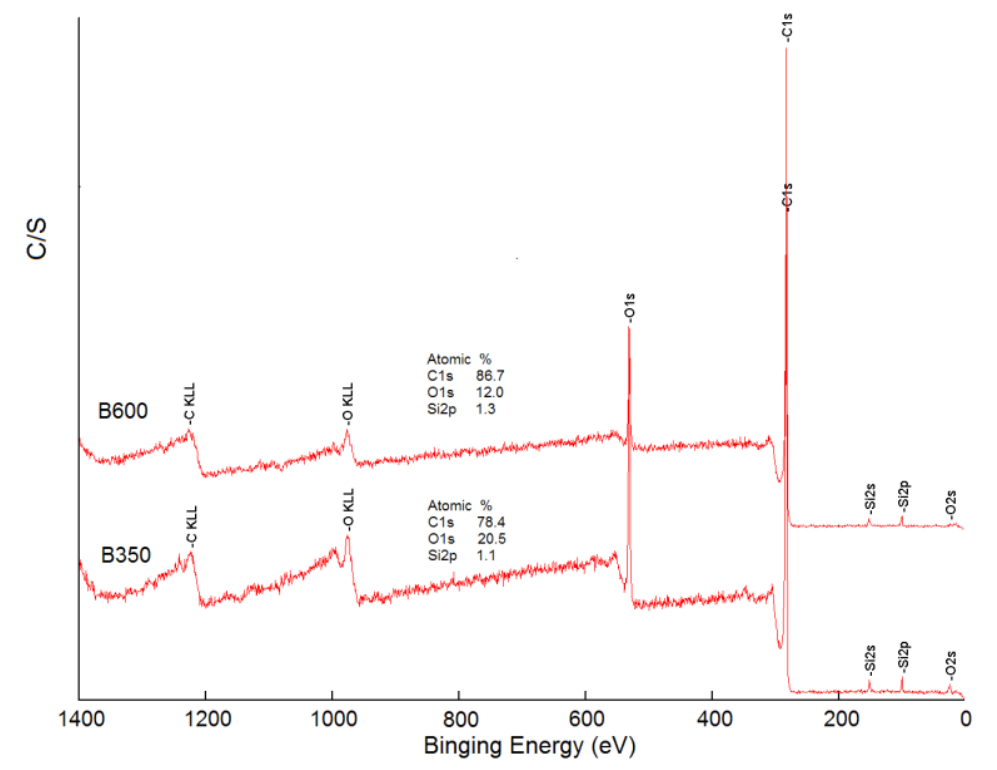

Fig. 5 - The XPS spectra of the biochar samples.
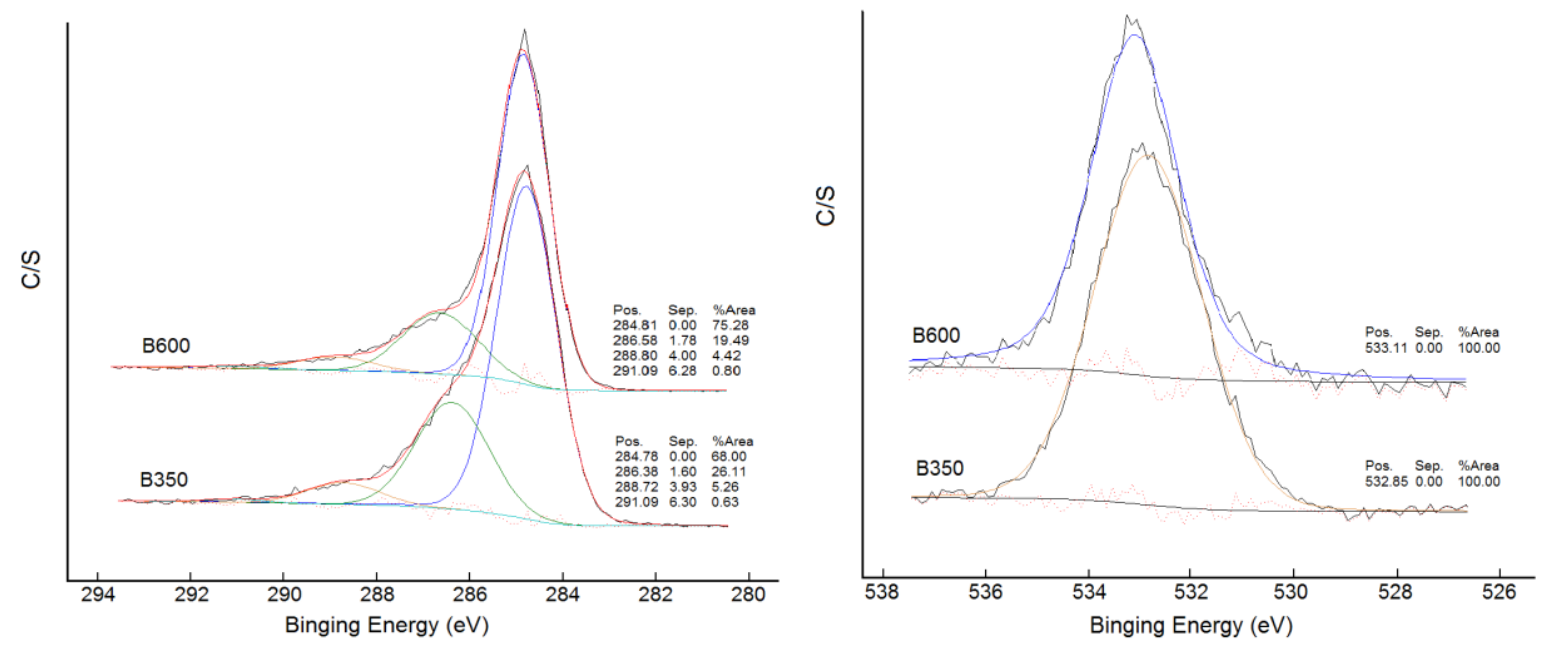

Fig. 6 - XPS spectra of $\mathrm{C}_{1 \mathrm{~s}}(\mathrm{a})$ and $\mathrm{O}_{1 \mathrm{~s}}(\mathrm{~b})$ in the biochars. 


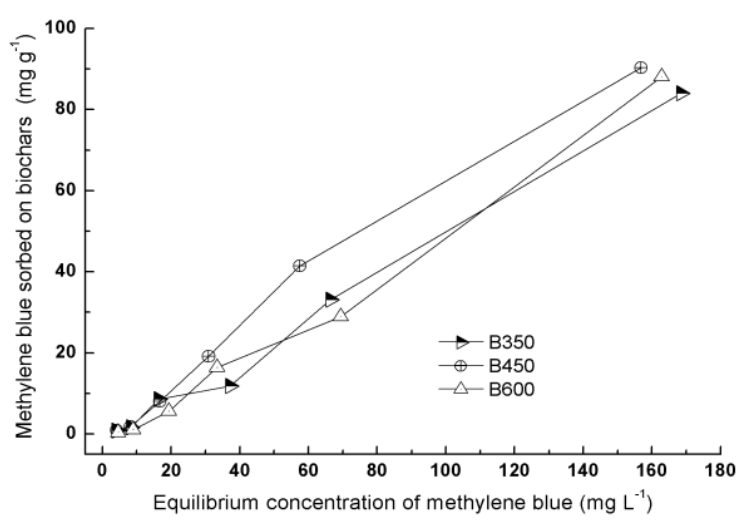

Fig. 7 - Sorption isotherms for $\mathrm{Pb}(\mathrm{II})$ and $\mathrm{MB}$ onto biochars.

\subsection{Sorption of $\mathrm{Pb}(I I)$ and methylene blue onto the pristine biochars}

The equilibrium adsorption capacities of all the tested biochars increased with increasing equilibrium $\mathrm{Pb}$ (II) concentration in the range of 0 to $50 \mathrm{mg} \mathrm{L}^{-1}$ and reached a plateau above that range (Fig. 7), suggesting the Type $\mathrm{L}$ (Langmuir) adsorption isotherm for $\mathrm{Pb}(\mathrm{II})$. There were great differences on the adsorption isotherm of $\mathrm{Pb}(\mathrm{II})$ and $\mathrm{MB}$ (Fig. 7). The equilibrium adsorption capacities increased quasilinearly with increasing equilibrium MB concentrations, suggesting the Type $\mathrm{C}$ (constant partition) adsorption isotherm for MB. Therefore, only the sorption isotherm data of $\mathrm{Pb}(\mathrm{II})$ were fitted by using Freundlich, Dubinin-Radushkevich (D-R) and Langmuir isotherm models and all coefficients of determination $\left(R^{2}\right)$ were $>0.80$, suggesting the good fitting with those isotherm models. The Freundlich model is considered to be an empirical isotherm based on sorption on a heterogeneous surface of varied affinities [28]. The slope of $1 / \mathrm{n}$ indicates a normal Freundlich isotherm when $1 / \mathrm{n}<1$ and cooperative adsorption when $1 / \mathrm{n}>1.0 .1<1 / \mathrm{n}<0.3$ in the present study (Table 3), ranging between 0.1 and 0.5 , indicates easy adsorption. The constants for Dubinin-Radushkevich isotherm model [28, 29], Qm and $\mathrm{K}$, at a constant temperature of $22^{\circ} \mathrm{C}$ are listed in Table 3. The value of coefficient of determination indicates that the Dubinin-Radushkevich isotherm model fit well with the 
equilibrium experimental data as compared with the other models considered (Table 3). The maximum adsorption capacities obtained using Dubinin-Radushkevich isotherm model is similar to them obtained using the Langmuir isotherm model (Table 3). The mean free energy of adsorption, $E(\mathbf{E}=1 / \sqrt{2 \beta})$, gives information about sorption mechanism, physical or chemical. If it lies between 8 and $16 \mathrm{~kJ} / \mathrm{mol}$, the sorption process takes place chemically, while $\mathrm{E}<8 \mathrm{~kJ} / \mathrm{mol}$ suggests the physical sorption process [30]. The $E(\mathrm{~kJ} / \mathrm{mol})$ value is obtained as $8.25-9.05$ $\mathrm{kJmol}^{-1}$ (Table 3), suggesting the chemical sorption process in the present study.

Table 3 Isotherm model parameters for $\mathrm{Pb}$ sorption onto biochars

\begin{tabular}{|c|c|c|c|c|c|c|c|c|c|c|}
\hline & \multicolumn{3}{|c|}{ Langmuir isotherm } & \multicolumn{3}{|c|}{ Freundlich isotherm } & \multicolumn{4}{|c|}{ D-R isotherm } \\
\hline & \multicolumn{3}{|c|}{$\frac{1}{q_{\mathrm{e}}}=\frac{1}{q_{\mathrm{m}} K_{\mathrm{L}}} \frac{1}{C_{\mathrm{e}}}+\frac{1}{q_{\mathrm{m}}}$} & \multicolumn{3}{|c|}{$\log q_{\mathrm{e}}=\frac{1}{n} \log C_{\mathrm{e}}+\log K_{\mathrm{F}}$} & \multicolumn{4}{|c|}{$\mathbf{q}_{\mathbf{e}}=\mathbf{q}_{\mathbf{m}} * \exp \left(-\boldsymbol{\beta}(\mathbf{R T})^{2} *\left[\ln \left(1+\frac{1}{\mathbf{C}_{\mathbf{e}}}\right)\right]^{2}\right)$} \\
\hline & $\mathrm{q}_{\mathrm{m}}$ & $\mathrm{K}_{\mathrm{L}}$ & $\mathrm{R}^{2}$ & $\mathrm{~K}_{\mathrm{F}}$ & $1 / \mathrm{n}$ & $\mathrm{R}^{2}$ & $\mathrm{q}_{\mathrm{m}}$ & $\beta$ & $E$ & $\mathrm{R}^{2}$ \\
\hline B350 & 16.3 & 0.313 & 0.945 & 5216 & 0.239 & 0.906 & 16.9 & $6.54 \mathrm{E}-09$ & 8.75 & 0.990 \\
\hline B450 & 15.1 & 0.281 & 0.970 & 5472 & 0.213 & 0.921 & 15.8 & 7.34E-09 & 8.25 & 0.997 \\
\hline B600 & 12.2 & 0.332 & 0.910 & 5257 & 0.171 & 0.855 & 12.3 & $6.10 \mathrm{E}-09$ & 9.05 & 0.962 \\
\hline
\end{tabular}

Where $\mathrm{q}_{\mathrm{m}}$ : maximum adsorption capacity $\left(\mathrm{mg} \mathrm{g}^{-1}\right) ; \mathrm{K}_{\mathrm{L}}$ : Langmuir constant $\left(\mathrm{L} \mathrm{mg}^{-1}\right) ; \mathrm{R}^{2}$ : coefficient of determination; $K_{F}$ : affinity coefficient related to the bonding energy $\left(\mathrm{mg}^{(1-1 / n)} \mathrm{L}^{1 / n} \mathrm{~g}^{-1}\right) ; n$ : the heterogeneity factor which represents the bond distribution; $\beta$ : the isotherm constant $(\mathrm{mol} / \mathrm{J})^{2} ; \mathrm{R}$ : the gas constant $(8.314$ $\mathrm{J} / \mathrm{mol} \mathrm{K})$; and $\mathrm{T}$ : absolute temperature (K).

Langmuir isotherm is used to describe the monomolecular layer and homogeneous adsorption [28, 29]. Therefore, Langmuir adsorption isotherm confirms the monolayer adsorption of $\mathrm{Pb}$ (II) onto the biochar surface (Fig. 7). The dimensionless separation factor, $\mathrm{R}_{\mathrm{L}}$, can be obtained based on the Langmuir constant $\left(\mathrm{K}_{\mathrm{L}}\right)$ and the initial $\mathrm{Pb}(\mathrm{II})$ concentration (Co) $\left(\mathrm{R}_{\mathrm{L}}=1 /\left(1+\mathrm{K}_{\mathrm{L}} \mathrm{C}_{0}\right)\right)$. The value of $\mathrm{RL}$ indicates the type of isotherm to be unfavorable $\left(\mathrm{R}_{\mathrm{L}}>1\right)$, linear $\left(\mathrm{R}_{\mathrm{L}}=1\right)$, favorable $\left(0<\mathrm{R}_{\mathrm{L}}<1\right)$, or irreversible $\left(\mathrm{R}_{\mathrm{L}}=0\right)$. The $\mathrm{RL}$ values for the adsorption of $\mathrm{Pb}$ (II) onto the biochars for all studied initial $\mathrm{Pb}$ (II) concentrations were below 1, indicating that the sorption of $\mathrm{Pb}(\mathrm{II})$ onto the biochars was a favorable process. Langmuir adsorption 
capacities for $\mathrm{Pb}$ (II) ranged from 12.2 to $16.3 \mathrm{mg} \mathrm{g}^{-1}$ (Table 3), larger than most of the reported values in the literature such as $4.13 / 3.00 \mathrm{mg} \mathrm{g}^{-1}$ for pine wood/bark char, $2.62 / 13.10 \mathrm{mg} \mathrm{g}^{-1}$ for oak wood/bark char [31], 3.89-4.25 mg g ${ }^{-1}$ for pine wood biochar, and 1.84-2.40 $\mathrm{mg} \mathrm{g}^{-1}$ for rice husk biochar [32]. While Ding et al. [33] reported that the maximum sorption capacity of $\mathrm{Pb}(\mathrm{II})$ decreased from 21 to $6.1 \mathrm{mg} \mathrm{g}^{-1}$ as pyrolysis temperature increased from 250 to $600^{\circ} \mathrm{C}$ for sugarcane bagasse derived biochar, our results did not show clear difference in sorption capacity between B350 and B450. However, the maximum sorption capacity of B600 was apparently lower than that of $\mathrm{B} 350$ or $\mathrm{B} 450$. The potential sorption mechanisms for $\mathrm{Pb}(\mathrm{II})$ reported in the literature included cation exchange, precipitation, and intraparticle diffusion [33]. The dominant mechanism, however, depended on factors such as the pyrolysis temperature and types of biochar. For example, with dairy-manure derived biochar, which contained high levels of soluble phosphate, Cao et al. demonstrated that precipitation of $\mathrm{Pb}(\mathrm{II})$ with phosphate was the predominant sorption mechanism, and this explained why biochar derived at $200^{\circ} \mathrm{C}$ sorbed more $\mathrm{Pb}$ (II) than biochar derived at $350^{\circ} \mathrm{C}$ [34].

The linkage between sorption behavior and the physicochemical properties of biochars can be complex and needs to be interpreted on a case-by-case basis. Although adsorption phenomenon occurs mostly on the surface of the biochars, our data did not reveal a conclusive correlation between adsorption capacity for $\mathrm{Pb}(\mathrm{II})$ with specific surface areas of the studied biochars. For example, specific surface areas of the pristine biochars increased with increasing pyrolysis temperature (Table 1) $[8,21]$; yet the adsorption capacity for $\mathrm{Pb}(\mathrm{II})$ did not follow the this pattern. Negative zeta potential values were found for all the studied biochars, which were consistent with the previous reports $[16,35]$. This indicates that the biochars carried negative charges on their surfaces were more likely to adsorb positively charged ions such as $\mathrm{Pb}(\mathrm{II})$. This 
is confirmed by the cation-exchange capacity, which reflects the ion exchangeable potential and surface negative charges on biochars. Surface acidic functional groups (carboxyl, lactone and phenol) of biochars analyzed by Boehm titration varied with the peak pyrolysis temperature. The anions of surface functional groups can form surface complexes with $\mathrm{Pb}(\mathrm{II})$ on the biochars and thus increased specific adsorption $[16,36]$. XPS analyses indicated that $\mathrm{C}$ and $\mathrm{O}$ were the main surface elements for those studied biochars and they were impacted by the peak pyrolysis temperature (Fig. 5).

\section{Conclusions}

The pyrolysis temperature has different effects on biochar's elemental composition, physicochemical properties and surface elemental species. Contents of $\mathrm{O}$, atomic ratios of $\mathrm{O} / \mathrm{C}$ and $(\mathrm{O}+\mathrm{N}) / \mathrm{C}$ and total acidic groups of biochars decreased while $\mathrm{C}$ contents, specific surface areas increased with the increasing pyrolysis temperature from $350^{\circ} \mathrm{C}$ to $600^{\circ} \mathrm{C}$. Quartz and calcite were confirmed by XRD analyses in the biochar under the pyrolysis temperature of $600^{\circ} \mathrm{C}$. FT-IR verified the changes on surface functional groups of the biochars under different pyrolysis temperature. X-ray photoelectron spectroscopy analyses show that the increasing pyrolysis temperature only changes the surface contents of $\mathrm{C}$ and $\mathrm{O}$. The batch equilibrium adsorption of all the tested biochars shows that $\mathrm{B} 350$ had higher adsorption capacities of $\mathrm{Pb}$ (II) than other biochars. Therefore, bulk elemental composition, specific surface area, surface electronegativity and XPS analyses can effectively characterize and screen the surface properties of biochars for wastewater treatment.

\section{Acknowledgments}


This work was partially supported by the Natural Science Fund of Jiangsu Province (BK20131268) and the NSF (CBET-1054405). 


\section{References}

[1] J. Lee, M. Kidder, Evans BR, S. Paik, A.C. Buchanan, C.T. Garten, R.C. Brown, Environ. Sci. Technol., 44 (2010) 7970-7974.

[2] M. Ahmad, A.U. Rajapaksha, J.E. Lim, M. Zhang, N. Bolan, D. Mohan, M. Vithanage, S.S. Lee, Y.S. Ok, Chemosphere, 99 (2014) 19-33.

[3] D. Mohan, A. Sarswat, Y.S. Ok, C.U. Pittman, Bioresource Technol., 160 (2014) 191-202.

[4] T.M. Abdel-Fattah, M.E. Mahmoud, S.B. Ahmed, M.D. Huff, J.W. Lee, S. Kumar, J. Ind. Eng. Chem., 22 (2015) 103-109.

[5] S.E. Elaigwu, V. Rocher, G. Kyriakou, G.M. Greenway, J. Ind. Eng. Chem., 20 (2014) 3467-3473.

[6] B. Singh, B.P. Singh, A.L. Cowie, Aust. J. Soil Res., 48 (2010) 516-525.

[7] Z.A. Mayer, Y. Eltom, D. Stennett, E. Schroder, A. Apfelbacher, A. Hornung, Environ. Prog. Sustain. Energy, 33 (2014) 490-496.

[8] A. Mukherjee, A.R. Zimmerman, W. Harris, Geoderma, 163 (2011) 247-255.

[9] L.W. Low, T.T. Teng, A.F.M. Alkarkhi, N. Morad, B. Azahari, J. Ind. Eng. Chem., 28 (2015) $37-44$.

[10] Y. Wang, Y.T. Hu, X. Zhao, S.Q. Wang, G.X. Xing, Energ. Fuel., 27 (2013) 5890-5899.

[11] J.J. Manya, Environ. Sci. Technol., 46 (2012) 7939-7954.

[12] S. Kloss, F. Zehetner, A. Dellantonio, R. Hamid, F. Ottner, V. Liedtke, M. Schwanninger, M.H. Gerzabek, G. Soja, J. Environ. Qual., 41 (2012) 990-1000.

[13] S.S. Wang, B. Gao, A.R. Zimmerman, Y.C. Li, L.N. Ma, W.G. Harris, K.W. Migliaccio, Chemosphere, 134 (2015) 257-262.

[14] Y. Sun, B. Gao, Y. Yao, J. Fang, M. Zhang, Y. Zhou, H. Chen, L. Yang, Chem. Eng. J., 240 
(2014) 574-578.

[15] M. Inyang, B. Gao, Y. Yao, Y. Xue, A. Zimmerman, A. Mosa, P. Pullammanappallil, Y. Ok, X. Cao, Crit. Rev. Env. Sci. Tec, 46 (2016) 406-433.

[16] W. Ding, X. Dong, M. Inyang, B. Gao, L.Q. Ma, Chemosphere, 105 (2014) 68-74.

[17] M. Uchimiya, L.H. Wartelle, K.T. Klasson, C.A. Fortier, I.M. Lima, J. Agr. Food Chem., 59 (2011) 2501-2510.

[18] S.L. Goertzen, K.D. Theriault, A.M. Oickle, A.C. Tarasuk, H.A. Andreas, Carbon, 48 (2010) $1252-1261$.

[19] A.M. Oickle, S.L. Goertzen, K.R. Hopper, Y.O. Abdalla, H.A. Andreas, Carbon, 48 (2010) 3313-3322.

[20] R.B. Fidel, D.A. Laird, M.L. Thompson, J. Environ. Qual., 42 (2013) 1771-1778.

[21] M. Keiluweit, P.S. Nico, M.G. Johnson, M. Kleber, Environ. Sci. Technol., 44 (2010) $1247-1253$.

[22] Z.M. Chen, B.L. Chen, C.T. Chiou, Environ. Sci. Technol., 46 (2012) 11104-11111.

[23] M. Zhang, B. Gao, Y. Yao, Y.W. Xue, M. Inyang, Sci. Total. Environ., 435 (2012) 567-572.

[24] J. Jaramillo, P.M. Alvarez, V. Gomez-Serrano, Appl. Surf. Sci., 256 (2010) 5232-5236.

[25] J. Lehmann, Front. Ecol. Environ., 5 (2007) 381-387.

[26] J.W. Gaskin, C. Steiner, K. Harris, K.C. Das, B. Bibens, T. ASABE, 51 (2008) 2061-2069.

[27] S. Kang, X. Li, J. Fan, J. Chang, Ind. Eng. Chem. Res., 51 (2012) 9023 - 9031.

[28] K.Y. Foo, B.H. Hameed, Chem. Eng. J., 156 (2010) 2-10.

[29] Y. Liu, Y. Liu, Sep. Purif. Technol., 61 (2008) 229-242.

[30] F. Helfferich, McGraw Hill, New York, USA, (1962) 166.

[31] D. Mohan, C.U. Pittman, M. Bricka, F. Smith, B. Yancey, J. Mohammad, P.H. Steele, M.F. 
Alexandre-Franco, V. Gomez-Serrano, H. Gong, J. Colloid Interf. Sci., 310 (2007) 57-73.

[32] Z.G. Liu, F.S. Zhang, J. Hazard. Mater., 167 (2009) 933-939.

[33] W.C. Ding, X.L. Dong, I.M. Ime, B. Gao, L.Q. Ma, Chemosphere, 105 (2014) 68-74.

[34] X.D. Cao, L.N. Ma, B. Gao, W. Harris, Environ. Sci. Technol., 43 (2009) 3285-3291.

[35] X.J. Tong, J.Y. Li, J.H. Yuan, R.K. Xu, Chem. Eng. J., 172 (2011) 828-834.

[36] M. Inyang, B. Gao, A. Zimmerman, Y.M. Zhou, X.D. Cao, Environ. Sci. Pollut. R, 22 (2015) 1868-1876. 

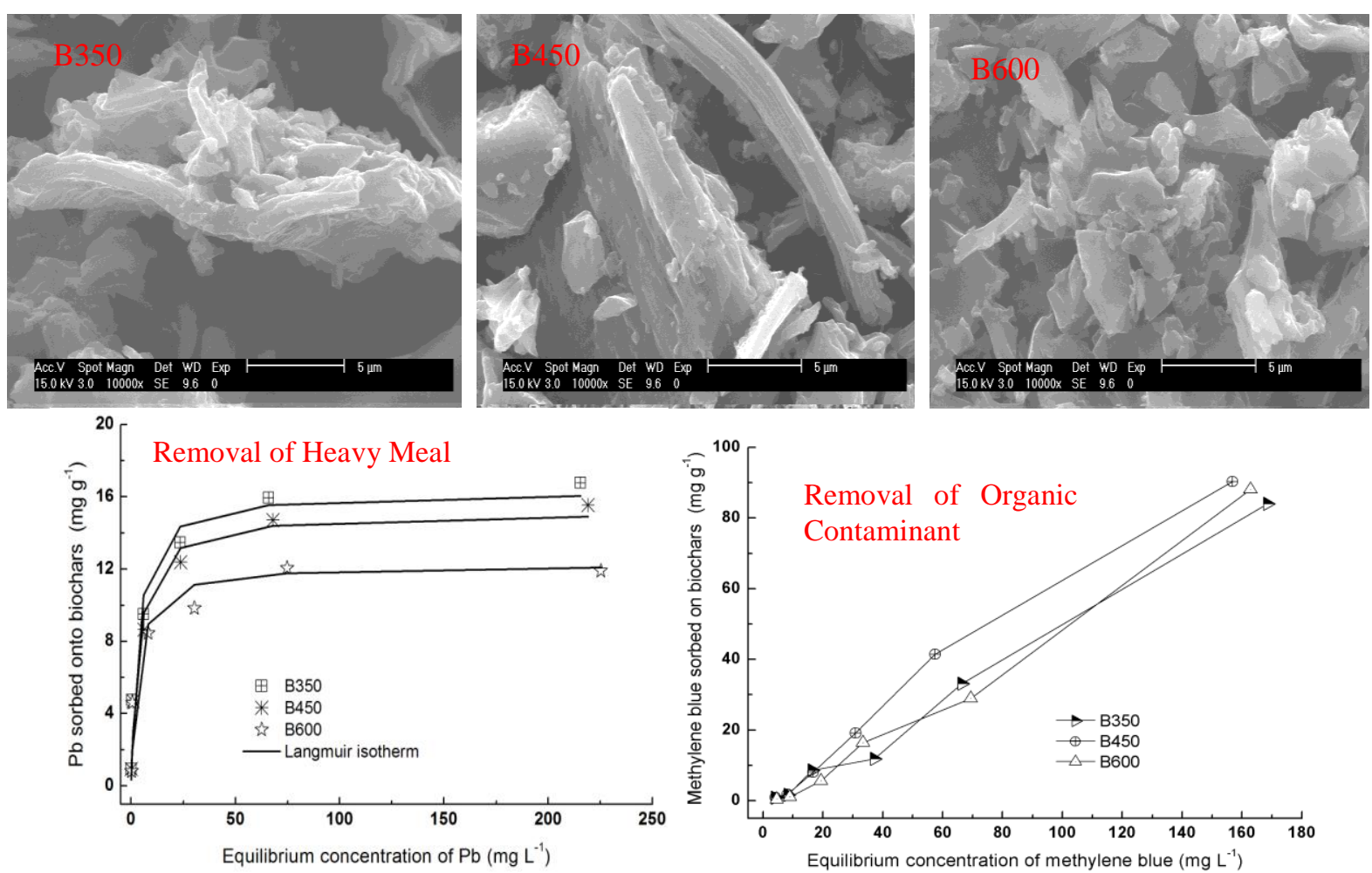